\title{
Diversity and power in the English hotel conversations textbook
}

\author{
Roohani, Ali $\bowtie$ \\ Shahrekord University, Iran (roohani.ali@gmail.com) \\ Sheikhipour, Anahita \\ Shahrekord University, Iran (Anahita.sheikhipour@gmail.com \\ Farhang, Maryam \\ Shahrekord University, Iran (Mary.farhang67@gmail.com)
}

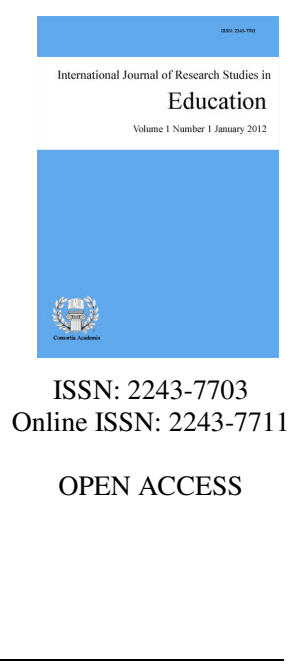

\section{Abstract}

Instructional textbooks can be powerful tools which construct our social identities. Also, the way males and females are represented in the instructional textbooks can affect the pictures that learners develop about males and females in the society. The study, thus, investigated the visual representation of gender in power positions and examined the frequency of the ethnic groups in power positions in English Hotel Conversations, a textbook on hotel management and tourism. To this end, content analysis was carried out through counting and analyzing the pictures/images of the textbook in terms of power, gender, and ethnic groups. The results of picture analysis indicated that the pictures of males in positions of power were more than those of females. Moreover, most of the high prestigious jobs were represented through male characters. Ethnic portrayal was another important social factor in the textbooks. Only a small number of pictures represented the people from various ethnic groups. The findings suggest that this hotel management textbook needs to be adapted to include various ethnic groups and balance power equality.

Keywords: textbooks; gender; power; ethnicity 


\section{Diversity and power in the English hotel conversations textbook}

\section{Introduction}

Over the past decade, tourism industry has significantly gained momentum worldwide, including in Iran. Therefore, authorities across the world try to provide people with better facilities. One of the important steps in facilitating travelling is promoting hotels and resorts. Hotel management, particularly in Iran, is one of the main issues to be considered. The staff working in hotels needs to be trained to be able to communicate properly, especially with foreign tourists. Thus, the staff should be able to speak English in order to communicate better with hotel guests and be able to offer them a better service, which leads to job satisfaction. Therefore, the textbooks for students have a great role; the textbooks should be designed effectively in order to make them ready for their job in the future. Van Dijk (1998) believes that printed materials such as textbooks play a crucial role in inculcating stereotypic thinking in students and in setting their expectations. Weninger and Williams (2005) have a similar view, especially for children; they mention that "Children's picture and literature books are a significant source of information about the world children live in. They simultaneously reflect and teach cultural values and norms" (p. 159). Ndura (2004) states that the content of textbooks and educational materials has a great impact on students' beliefs toward themselves, and other members of society. In each society, textbooks play a prominent role in creating students' worldview of female and male genders (Kobia, 2009). As explained by Dominguez (2003), English language teaching (ELT) textbooks are a good example of effecting learning implicitly and absorbing personal biases and cultural prejudices for English as a foreign language (EFL) learner. Tajeddin \& Janebi Enayat (2010) concluded that "the manner in which male and female genders are portrayed in textbooks can highly affect the images that learners develop of male and female in the society."

"It is important for second or foreign (L2) learners and teachers to regard textbooks as more than only linguistic devices. Besides, more attention should be paid to how ELT textbooks can affect certain agendas (Roohani \& Heidari, 2012, p. 125). Textbooks can be used to facilitate the combination of content about ethnically, racially, and culturally diverse populations (Sileo \& Prater, 1998). According to research studies over the past 20 years, the conceptions of gender in students' textbooks, influence students' point of view toward everything, manner, and a sense of self (Visser, 2002). Textbooks and educational ideals are closely integrated; therefore, the role and impact of textbooks need a thorough investigation (Gullicks, Pearson, Child, \& Schwab, 2005). Attempt was made in the present study to analyse the English Hotel Conversations textbook (Atri, 2017) in terms of diversity, gender, and power relations. The textbook is designed to help students of hotel management and tourism get familiar with the register related to hotel management and tourism. The related sentences and phrases in the textbook come along with pictures/images in different situations with sample conversations. In order to analyse the power relations and gender, in general, and in power positions, and to find out about the diversity of ethnic groups, this study focused on the photos of the English for academic/specific purpose (EAP/ESP) textbook. To the best of the current researchers' knowledge, none of the previous studies have delved into the issue of diversity and power in the English Hotel conversation textbook, widely taught in Iran. In light of these issues, this study sought to evaluate the English Hotel conversation textbooks through analyzing pictures to figure out which ethnicity and gender were prominently represented. The findings can make a contribution for better developing ESP/EAP textbooks.

\section{Literature Review}

\subsection{Power and Education}

Keating (2009) defines power as "the ability or capacity to perform or act effectively, the ability or capacity to exert control over others, moral efficacy, authority and influence" (p. 997). Weedon (1987) believes that the 
education system is at the center of the materials of power. Also, Apple (1990) claims that schools contribute to inequality in education system because they are organized to differentially distribute specific kinds of knowledge. "When a language or a system of written representation is taught in school or has a religious or secular literature, it is a more powerful tool in the management of social stratification and the wide representation of ideas" (Keating, 2009, p. 1002). She points out that "power and language are connected through the marking of certain encounters and contexts as requiring particular types of language use, the privileging of certain types of language", such as the importance of considering the speech acts as one is involved in a conversation (p. 996).

Harrison (2010) categorizes the relationship between power and society based on anthropological studies as follows:

$>$ Physical environment plays a great role in the development of power systems.

$>$ Power relationships are connected to the economic patterns of a culture.

$>$ Patterns of warfare are linked to the development of power relationships.

$>$ Anthropological studies show that power relationships exist in simple forms in primitive societies and that no society is void of a power structure.

Harrison (2010) states that people in a society are stratified based on a wide range of characteristics such as ethnicity or race, age, gender, religion, and so on. The system of stratification also influences different lifestyles, cuisines which we eat, magazines and books which we read, places of residence, schools where we attend, pronunciation and accent, recreational activities, and so forth (Harrison, 2010). The importance of textbooks and their substantial role in representing such characteristics in society is undeniable. Thus, this study sought to investigate how and to what extend these factors were exhibited throughout the book.

\subsection{Gender}

Oakley (1972) distinguishes the concept of gender from the concept of sex. Oakley points out that gender parallels the biological division of sex into male and female, but it involves the division and social valuation of masculinity and femininity. Studies show that gender is part of our identity which consciously and unconsciously affects our self-image and interpersonal attitudes (Tajeddin \& Janebi Enayat, 2010). Gender roles are the result of the interactions between individuals and their environments, and they inform people about what type of behavior is accepted and appropriate for each sex. Males and females are expected to perform certain tasks and occupy different roles based on their sex at work (Kantar, 1977). Gender roles are attributed based on stereotypes about them. For example, women are considered emotional while men are considered rational (Blackstone, 2003). Cameron (1990, as cited in Gharbavi \& Mousavi, 2012, p. 42) states that "gender-biased language in textbooks can affect students adversely and it creates an oppressive world for them because this gender-biased language most often is unjustified and unfair." Lesikin (2001) believes that studies on gender bias and gender stereotypes showed that some texts and pictures which contain stereotypic connotations would have harmful effect on female students. Then, Gharbavi and Mousavi (2012, p. 42) maintain that "these effects include feelings of exclusion, devaluation, alienation and lowered-expectations."

Elliott and Woodward (1990) argue that it was not until the 1960s that concern about misrepresentation and underrepresentation of women and minorities in textbooks became a visible issue. The results of the study done by Gullicks, Pearson, Child, and Schwab (2005) on diversity and power in public speaking textbooks, showed that the frequency of men in positions of power represented in pictures in the top 10 public speaking textbooks was more than women. In a different view, Mineshima (2008) carried out a research to see how the images in an EFL textbook used in upper secondary English classes in Japan represented the genders. The results revealed that in this upper secondary EFL textbook both genders were represented equally in terms of male and female characters, their speeches, number of occupations, and family roles. 
Tajeddin and Janebi Enayat (2010) studied gender representation and stereotyping in ELT Textbooks. They investigated the positioning of gender in the images of three international and local ELT textbooks: New Headway, Top Notch, and Iran Language Institute (ILI) English Textbook. The results indicated that men were represented to be more active, competent, socially important, breadwinners, and powerful. While women appeared as less active and more reactive, and socially less powerful. Another study was done by Ullah and Skelton (2013) in school textbooks of Pakistan. The research aimed to develop a view of gender equality based on students' consciousness by the presence of more positive gendered pictures in their textbooks. The investigations showed that there were some biases toward choosing images for textbooks in Pakistan. In the Ullah and Skelton's study, 24 textbooks from gendered biased aspects were analyzed (Urdu, English and Social Studies), and qualitative content analysis approach was utilized. Ullah and Skelton (2013) found out that, "despite the prevailing claims of achievements, the new textbooks are ideologically invested - and contribute to the perpetuation of gender inequality. In this context, the gender blindness of the curriculum designers and textbook authors is a matter of serious concern" (p. 183).

In a similar vein, Cawyer et al. (1994) found that males in the pictures of textbooks would be in more powerful or dominant activities. Likewise, Stockdale (2006) examined gender representation in an EFL textbook called Impact Values. The results revealed that men were more visible in all the categories, and the textbook had bias toward men and overshadowed the presence and voice of women.

\title{
2.3 Ethnicity
}

Gillborn (1990) in his book, Race, Ethnicity and Education, noted that 'race' is one of the most controversial matters, and it is more related to political and key issues in the realm of educational. He believes that the word ethnic group is often used mistakenly with 'ethnic minority'. "The latter is usually taken as implying minority status not only in numerical terms, but also in power terms." (Gillborn, 1990, p. 4). Shimahara, Holowinsky, and Tomlinson-Clarke (2008) believe that race has a social and political meaning. In another definition by Wallman $(1979$, p. x), the focus is put on the "sense of difference which can occur where members of a particular [ethnic] group interact with non-members. Real differences between groups of people are no more (and no less) than potential identity markers for the members of those groups.” According to Giddens (1989):

\begin{abstract}
Members of ethnic groups see themselves as culturally distinct from other groupings in a society, and are seen by those others to be so. Many different characteristics may serve to distinguish ethnic groups from one another, but the most usual are language, history or ancestry (real or imagined), religion, and styles of dress or adornment. Ethnic differences are wholly learned. (pp. 243-244)
\end{abstract}

In contrast, Lacy (1988, cited in Gillborn, 1990) is one of those scholars who believes that educational system does not play a significant role in the problem of racism. Lacey believes that

\begin{abstract}
Schools cannot 'solve' the problem of racism in our society. But they should surely not contribute to it, to the extent that they do. There is no simple or doctrinaire solution to the problem but the teaching profession can make a much larger contribution than they do at present. (Gillborn, 1990, p. 1)
\end{abstract}

Many investigations have been done on the role of ethnic groups in textbooks. Weninger and Williams (2005) were among those researchers who conducted a study on presence of ethnic or national minorities in Hungarian elementary school textbooks. An available sample which consists of more than three fourths of first and fourth grades was gleaned from three academic and public libraries in Hungary. In their research, they analyzed the content, images, stories, reading, and literature books to find out the presence of different ethnic groups or national or cultural minorities. Findings indicated that the textbook's authors did not pay much attention to minorities in Hungarian school textbooks, or when they rarely showed up, they contained some stereotypical ideas. Also, Weninger and Williams (2005) argued that school textbooks are cultural objects that influence 
relations between the majority and minorities.

Ndura (2004) did a study on the design and adaptation of ESL textbooks. In this research, five strategies were introduced to tackle with cultural biases and stereotypic attitudes in English as a second language (ESL) materials. The first strategy was "becoming aware", which means teachers should be aware of the different types of bias and their influence on students' attitudes and understandings. The second strategy was to "critically examine instructional materials" (p. 150). The third strategy was to use some supplementary teaching materials. "Biographies, news clips, newspaper articles, television shows, fieldtrips, music and guest speakers from the community are only a few examples of resources that can be used to provide the students with more diversified and inclusive instruction" (p. 151). The fourth strategy was to "avoid the avoidance game". In real-life situations, students are expected to choose between right and wrong, trust and deceit, love and hate, acceptance and intolerance, victory and defeat, knowledge and ignorance, to name but a few. Therefore, avoiding such themes does not seems warranted, and students must be exposed to issues in their textbooks. Last but not least, listening to the students was another strategy. As each student comes from a different culture and has different background knowledge about the world around them, it would be a useful strategy to listen to each student individually to find out about their personal experiences. Despite the large bulk of studies on gender and ethnic or cultural groups, few studies have addressed the relationship between diversity and positions of power. Thus, this study aimed to investigate the frequency of ethnic groups and different genders in positions of power in English Hotel Conversations, a textbook about hotel management and tourism. Having the above as background, this study sought to answer the following questions:

1. What is the frequency of gender in positions of power in English Hotel Conversations?

2. What is the frequency of ethnic groups in positions of power in English Hotel Conversations?

\section{Method}

\subsection{Materials}

In order to find out the position of power for different genders and the proportion of variety of ethnics in hotel management textbooks, the best seller textbook on hotel management in Iran i.e., English Hotel conversations, written by Omid Atri in 2017 was selected for content analysis. This textbook consists of 22 units which are based on real situations in the hotel. In this textbooks, 10 units include sample conversations in the hotel. There are some exercises at the end of each unit. Besides, the textbook provides the learners with a list of hotel vocabulary, together with the definition, at the end of the book. There are audio files for all conversations in the textbook.

This textbook has been taught in many universities, like Niavaran University of Applied Science in Tehran, and in some language institutes, such as Marbin Hotel Management Center in Tehran and Danesh Pajoohan Institute in Mashhad, as well as in in several vocational schools, like Persian Hotel Management and Tourism Vocational School in Tehran. Basically, the essence of this textbook is conversation and consists of many pictures to show and clarify different occupations in hotels. This textbook contains a guide book, which consists of the translation of every single page and the author considers it to be useful for those who want to study on their own. The guide book has exactly the same organization as the original textbook. It includes a CD, which provides learners with audio files for getting to know the correct pronunciation and intonation. Also, the exercises have the audio files to increase students' listening skill and give them the chance to practice the roles through listening.

In the current study, only the pictures/images in the English Hotel Conversations textbook were investigated in order to find out about diversity in terms of ethnic groups, gender, and their relation with power positions. 


\subsection{Procedure}

This study was intended to analyze the pictures in the English Hotel Conversations textbook to show the relationship between power and gender and see which nationalities were represented the most. The total number of pictures were 221, but only 159 of them contained individuals. In this study, the pictures without the presence of people were not included. All the 159 pictures were colorful and included at least one of the genders. The pictures were analyzed in terms of power, gender, and ethnic groups, that is, to see if there were any differences in the number of male and female characters in the position of power and obtain the frequency of people representing ethnic groups in position of power.

To see how content analysis was done, the following includes one example of the picture of a female in position of power taken from the "Hotel in a Glance" section. Before the first unit in the textbook starts, there is a part, which is called "Hotel in a Glance" for the purpose of introducing different occupations and sections in the hotel. In the picture in Figure 1, there is a woman who is giving a presentation. This woman is in the position of power since she is standing in front of the class and talking about a figure on the board. It seems that this woman and the people in the room are not Iranians since they do not have hijab. As it is displayed, they are all white people, and most of the people in the room are female.

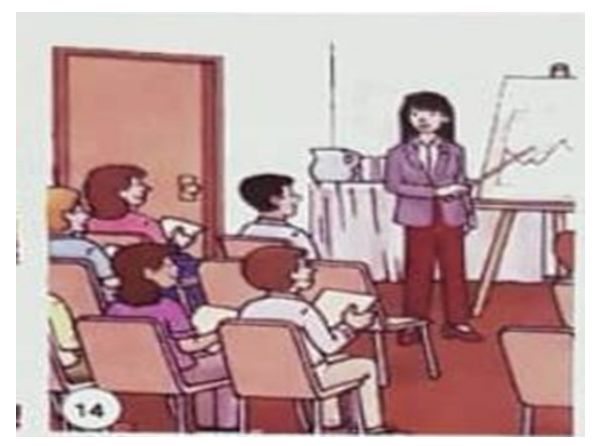

Figure 1. A woman in a meeting room and presenting a lecture (p. v)

\section{Results and Discussion}

The first unit was about greeting. The dialogues were presented through pictures. The majority of the people in the pictures of Unit 1 were white. Only four people (out of 45 people) were not white. It seems that the pictures were edited or modified in a way that females' heads were covered with scarves and their bodies were covered with clothes on. They are not naked or half-naked. The pictures in Figure 2 show the act of greeting by shaking hands or taping on the shoulder, but it is done between the people of the same gender. In one of the pictures which represents both genders, greeting is done without shaking hands because, based on the Islamic principles in Iran, it is forbidden to shake hands with people of another gender in public. Based on their names, none of the characters seem to be Iranians. As the last names suggest, they represent the people from different nationalities such as American, British, Chinese and Spanish.

Figure 2. Groups of people are greeting (p. 11)

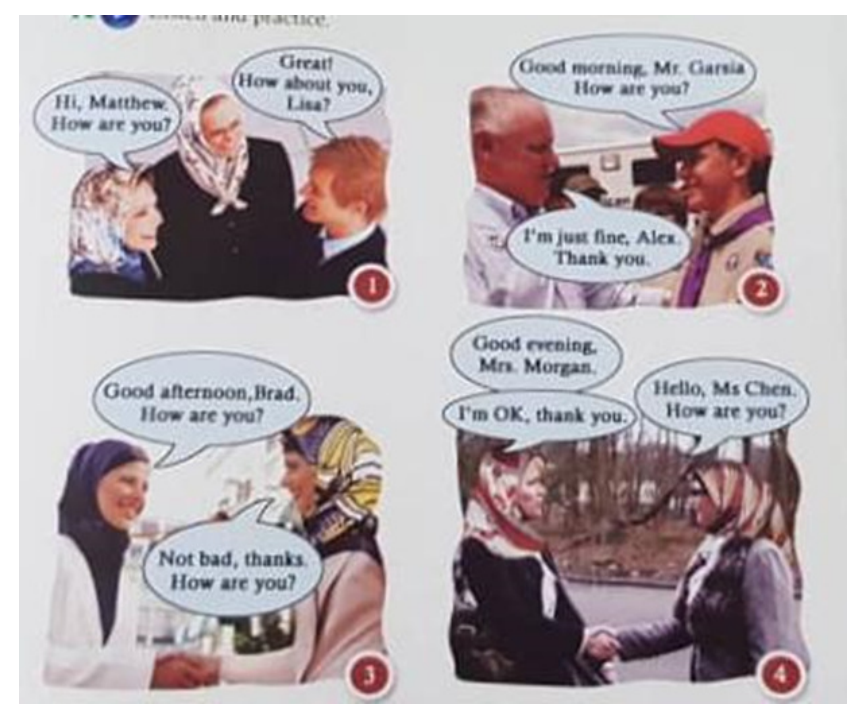


Figure 3 shows a picture, taken from Unit 1. It seems that the picture is original, and it is not edited. It represents females without hijab in the picture, in a context outside Iran. They are not Iranians, and both genders are shaking hands as a way of greeting. It seems that the people in the picture in Figure 3 wear formal clothes, indicating that they are in an office or a formal situation. In this picture, there are equal numbers of each gender.

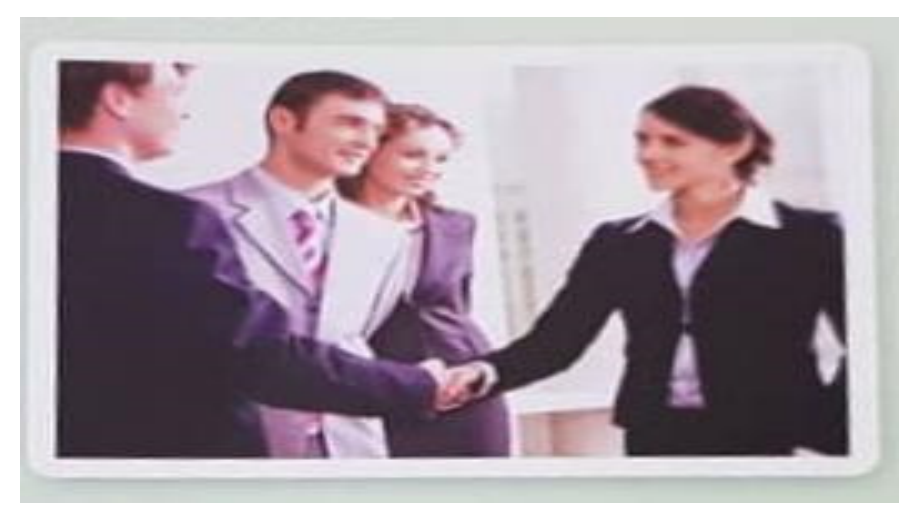

Figure 3. Greeting and shaking hands between different genders (p. 12)

The second unit dealt with conversations about booking a hotel room on the phone. In Unit 2, there were four pictures showing the receptionists: two male and two female receptionists. This result shows the equality of gender in job opportunities. However, there was no picture from any ethnic minorities, who are not white Americans or British. Likewise, in the third unit, which was about checking the guests in, there was a lack of pictures from different ethnic groups such as Persian, Turkish, Kurdish, or Chinese.

The fourth unit was about the guests' requests in a hotel. The pictures in Unit 4 were related to food and beverage staff as well as spa staff. There were three female and four male staff; two staff were from ethnic groups, that is, the South Asia. The picture in Figure 4 shows that an ethnic group was represented. However, the people from this ethnic group do not have a high status and high-level occupation like managing a hotel or being a staff trainer.

Figure 4. Staff from an ethnic group serving food in a hotel (p. 30)

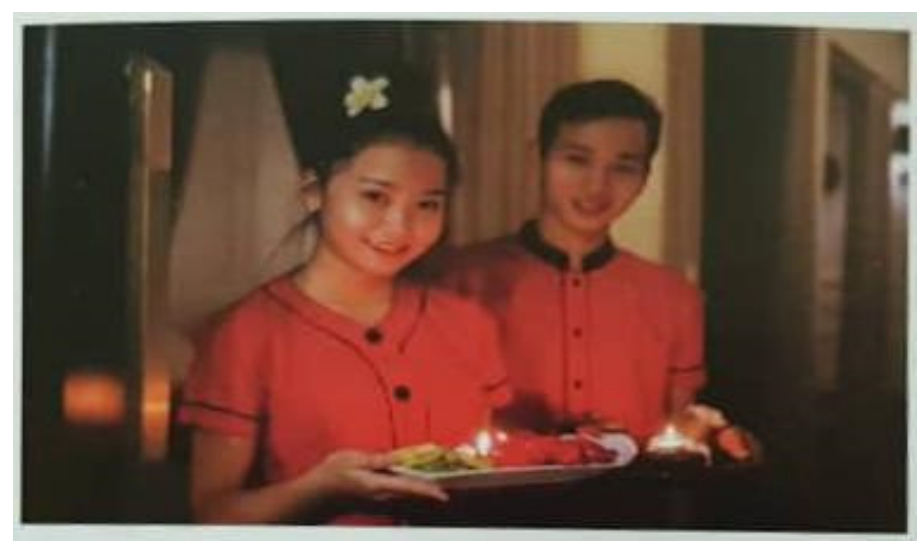

Unit 6 dealt with the guests' complaints in a hotel. The pictures in Unit 6 showed a female housekeeper and a female receptionist. There were two male guests who were complaining. Unit 7 had no pictures with the presence of humans. Almost all the pictures in Unit 8 showed staff from different ethnic groups, and both genders were represented fairly in the pictures. A different photo was also included in this unit. It was about a spa salon; As Figure 5 shows, this picture represents two men giving or receiving the massage. Only males were represented in the picture since females cannot be represented, given the topic and norms in Iran. Thus, the author of the textbook had selected males for this topic, following the principles and norms in Iran. 
Figure 5. Two men in a spa salon (p. 56)

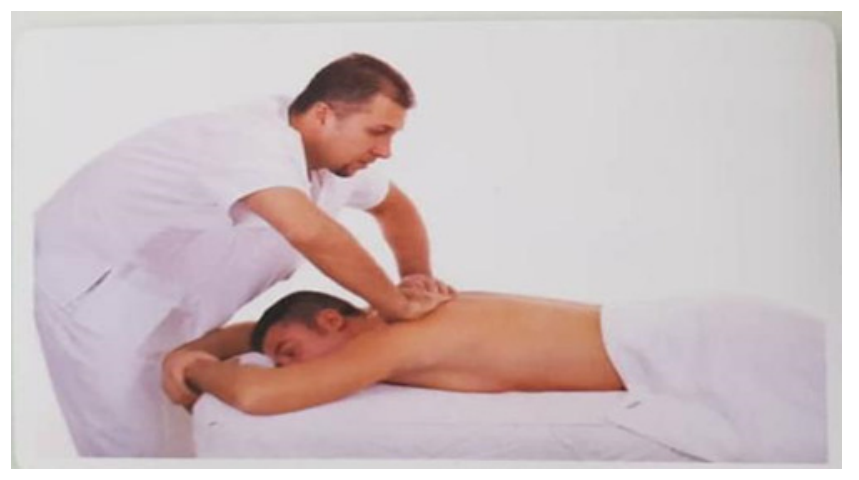

In the next three units, the textbook would present some grammar points and several speech acts. It would provide the learners with some dialogues and pair group tasks. The units would be followed by three series of worksheets. However, in Unit 14, the presence of a black man near a white woman on the bus was observed. In Unit 16, students were provided with several occupations at a hotel, such as chefs, receptionists, and managers. In this unit, females were more in charge of jobs like presenters, teachers, and babysitters. Figure 6 taken from Unit 16 shows two female clerks, who work at the child care center of the hotel. They are from ethnic minorities. Figure 7 taken from Unit 16 shows a woman as a coordinator in a meeting, and Figure 8 taken from Unit 16 shows a female trainer who is training the staff. None of the individuals in the pictures are Iranian.

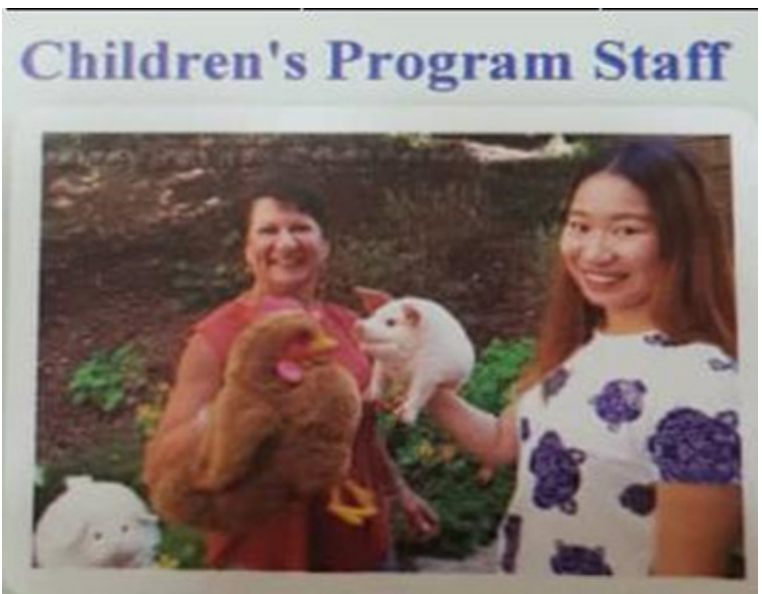

Figure 6. Two women entertaining guests' kids (p. 104)

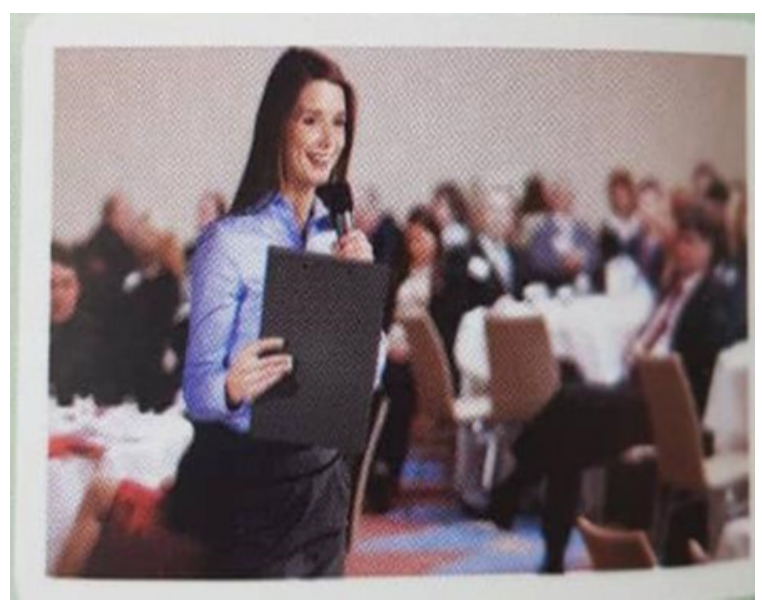

Figure 7. A woman planning and coordinating events in a meeting (p. 104)

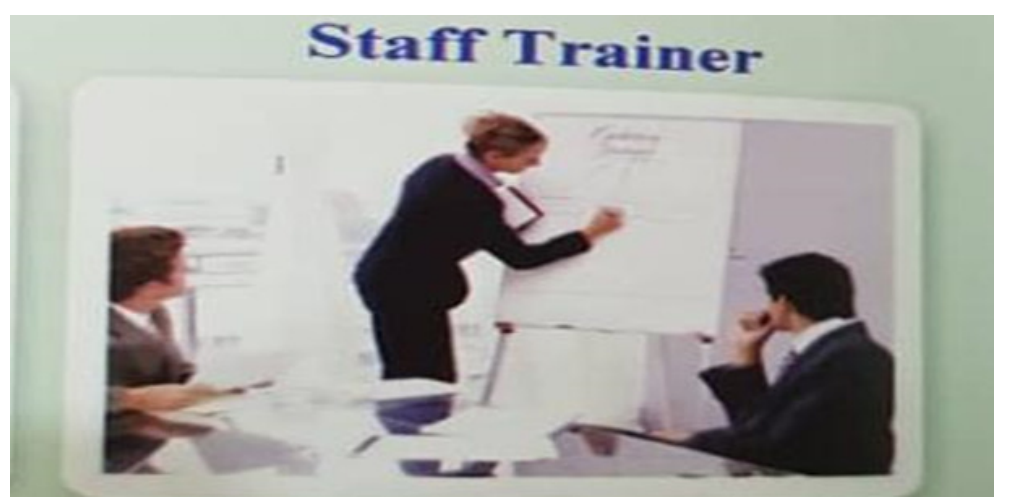

Figure 8. A woman training and evaluating the staff performance (p. 104) 
As Figure 9 displays, men usually are in charge of fixing things like plumbing. In Figure 10, a man is represented in a health center assisting another man, perhaps because women cannot be represented half-naked in the textbook. Moreover, the content analysis showed that many prestigious jobs, such as being a general manager, personnel director, or supervisor, were occupied by white males. Figures 11-13 represent white men as in high-positon jobs such as general managers, personnel directors, or supervisors.

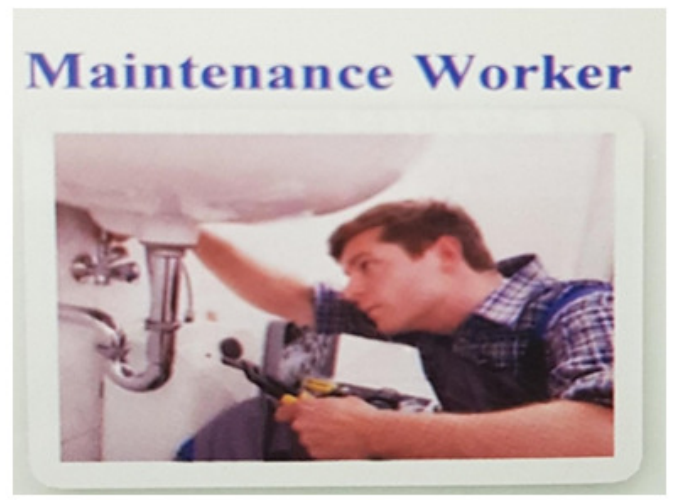

Figure 9. A plumber or a man fixing things (p. 104)

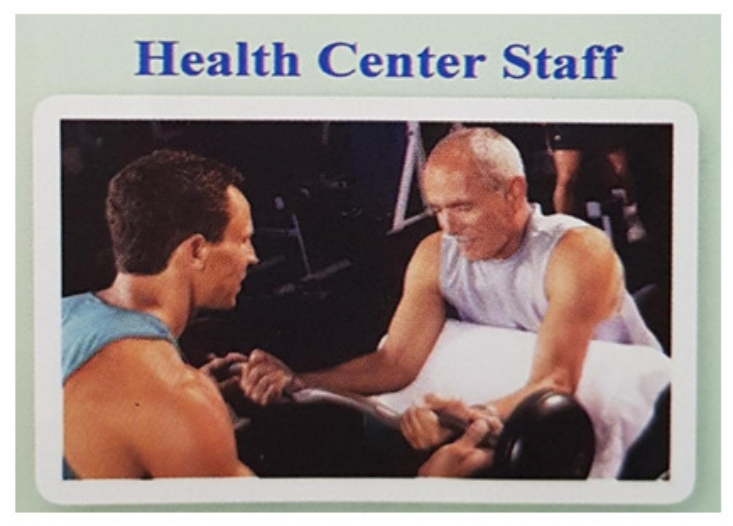

Figure 10. A man as a health center staff assisting another in the gym (p. 104)

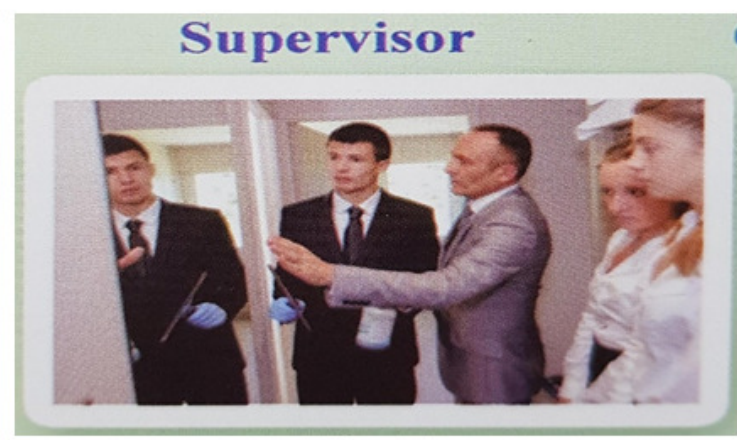

Figure 12. A man as a supervisor (p. 104)

Figure 11. A white man as a boss (p. 104)

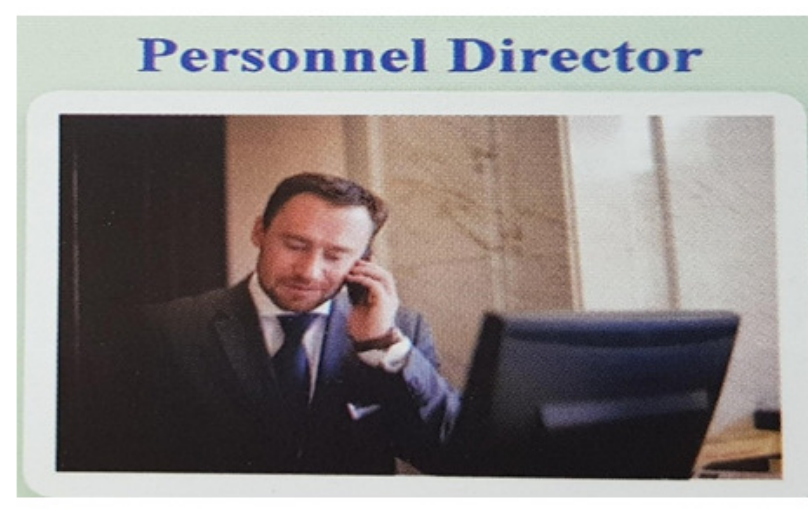

Figure 13. A white man as a personnel director (p. 104)

However, in a picture in Unit 18, a man is carrying a baby carriage and walking near a woman who wears a headscarf (hijab). This is partially in contrast to stereotypical images where a woman is represented as a mother and a man as a breadwinner. A man is in charge of looking after his kid. A woman is not the only person who looks after her children. This picture shows that both genders are represented and there is no gender bias in representing them. However, from ethnic point of view, it seems that the people in the picture are white and do represent the people from third world countries. 


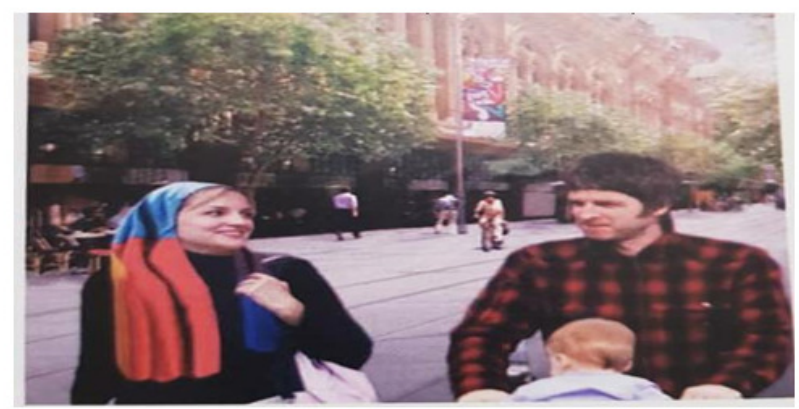

Figure 14. A man is carrying a baby carriage (p. 118)

In order to answer the first question, all the pictures which included a human were counted. In total, there were 124 females and 172 males in the pictures. Also, it was found that males in positions of power were about $58 \%$ while females were $42 \%$. This result shows that there was a difference between the frequencies of male and female characters represented in the pictures in English Hotel conversations. Men were more than women in positions of power. That is to say, the frequency of gender in positions of power was unequal. Besides, men were represented more to hold the high positions in jobs, such as managers, directors, or supervisors. These findings are consistent with the results of the study carried out by Cawyer et al. (1994) and Tajeddin and Janebi Enayat (2010), who showed that females were represented in low positions in several communication and ELT textbooks.

Furthermore, picture analysis showed that only 20 (out of 159 pictures) included people from various ethnic groups such as Persian, Chinese, Singaporean, Spanish and so forth. From 296 people represented in the pictures, only 35 were from an ethnic group, that is, about $12 \%$. Moreover, the people from various ethnic groups were not represented to have high status positions. The English Hotel conversations textbook did not have enough representation of various ethnic/racial groups. The results related to representation of minority groups in the English Hotel conversations textbook were in line with the findings of Weninger and Williams' (2005) study which showed a lack of fair attention to ethnic groups in Hungarian elementary school textbooks.

The external evaluation of the English Hotel conversations textbook, which is written for hotel management and tourism students, conveyed the impression that this textbook had a balanced depiction of males and females, but after internal evaluation of the pictures, it was discovered that there were some differences, thought they were not great, in terms of the frequency of gender representation in the textbook. The number of males was more than that of females. Maybe, it is not so important if one gender is represented more than the other one, but is it very important that both genders are represented fairly in terms of power positons. Females should also be represented to hold high-statues positions. Although this textbook was designed for Iranian students of hotel management and tourism, there was not even one picture of Iranians in the textbook and many photos were related to other nationalities. The author of this textbook did not ignore females in the hotel management textbook, but he should have included more pictures of Iranian females in positions of power such $\mathrm{s}$ as hotel managers.

The overrepresentation of males in this study were in line with several studies conducted on textbook evaluation (e.g., Bailey \& Parkes, 1995; Hartman \& Judd, 1978; Hellinger, 1980; Porreca, 1984; Whiteley, 1996). The findings of these studies showed overrepresentation of males, whether in pictures or in the texts. Research also supports the gender imbalance in other textbooks (see Ahmad \& Shah, 2019; Chandran \& Abdullah, 2003; Hall, 2014; Khurshid, Gillaniz \& Hashmi, 2010; Seng, 2003). However, as Blumberg (2007) states, more recent textbooks have tried to resolve the issue of gender imbalance. This can prevent females' negative emotions and thoughts, such as the feelings of inferiority in the society (Amini \& Barjandi, 2012). Also, as Brugeilles and Cromer (2009) explain, gender balance in the educational system might be effective for making some progress in the society. 
Regarding the second research question of the study, the frequency of ethnic groups was small. This means that the English Hotel conversations textbook did not pay attention to the ethnic minorities. This result is consistent with the findings of the study by Liew (2007), who explored gender and ethnic presentations in Chinese and Malay primary school reading textbooks. The results demonstrated biasedness both in gender and ethnic minorities. In other words, the representation of ethnic majorities was dominant in the primary school reading book.

\section{Conclusion}

This study investigated the representation of gender in the visual materials in the English Hotel Conversations textbook. Also, it examined the frequency of the ethnic groups in the pictures in this textbook, which is written for students of hotel management and tourism. The results showed that males were overrepresented. They were represented more frequently in the visual materials. Moreover, females were depicted less as those having high-status occupations. Depicting females in low positions might make them underestimate their ability and prohibit them from burgeoning their talent and prevent them from taking active roles in the society. Textbook writers in the field of hotel management and tourism should not represent females for the purpose of adding attraction to their textbooks. Furthermore, the results on ethnicity showed fewer references to the ethnic minorities; that is to say, there was a low number of pictures with minority groups. Some bias was observed in choosing pictures. Due to the fact that educational system plays a great role in preparing students to communicate with people of minority groups in the society, a balanced representation of ethnic groups in EAP/ESP textbooks is required.

None of the pictures in the textbook, which is written for those Iranian readers interested in the field of hotel management and tourism, represented Iranian people. Also, it seems that some of the pictures of white American or British were edited to represent females in line with the norms in Iran. However, the pictures of Muslim women were not used in the textbooks. The findings of this research may help EAP/ESP textbook writers to be more careful in selecting pictures. The EAP/ESP textbook writers can pay attention to the issue of gender and social/racial ethnicity and make their textbooks more tangible for students by including various ethnic groups. Paying attention to these aspects is part of cultural teaching that can be included during the class time. EAP/ESP teachers should encourage their students to pay attention to visual content of their textbooks, and students should be exposed to diverse cultures, ethnic groups, and genders to promote intercultural reflection.

The present research has several limitations. For instance, the study was limited to only one hotel management textbook, written for Iranian EAP/ESP learners. Also, it used content analysis to address the issues of gender and ethnicity. Future research can employ a larger number of EAP/ESP textbooks in this field using different methodologies and instruments for data collection, such as interviews and questionnaires. Also, further research needs to address the teacher's reactions and behaviors with regard to gender and ethnic imbalance in such textbooks. As Sunderland (2000) states, there should be an attention shift from textbooks evaluation to the teacher's perceptions and behaviors. Thus, it is recommended that EAP or ESP textbook writers and educators take the above issues into account so as to develop better visual materials and adapt their textbooks.

\section{References}

Ahmad, M., \& Shah, S. K. (2019). A critical discourse analysis of gender representations in the content of 5th grade English language textbook. International and Multidisciplinary Journal of Social Sciences, 8(1), 1-24. https://doi.org/10.17583/rimcis.2019.3989

Amini, M., \& Birjandi, P. (2012). Gender bias in the Iranian high school EFL textbooks. English Language Teaching, 5(2), 134-147. https://doi.org/10.5539/elt.v5n2p134

Apple, M. W. (1990). Ideology and curriculum (2nd ed). New York: Routledge.

Atri, O. (2017). English hotel conversations. Tehran: Jungle Publication.

Bailey, B., \& Parkes, L. (1995). Gender: The not-so-hidden issue in language arts materials used in Jamaica. 
Roohani, A., Sheikhipour, A., \& Farhang, M.

Journal of Caribbean Studies, 17(2), 265-278.

Blackstone, A. (2003). Gender roles and society. In J. R. Miller, R. M. Lerner, \& L. B. Schiamberg (Eds.), Human ecology: An encyclopedia of children, families, communities, and environments (pp. 335-338). Santa Barbara: ABC-Clio.

Blumberg, R. L. (2007). Gender bias in textbooks: A hidden obstacle on the road to gender equality in education. Paris: UNESCO.

Brugeilles, C., \& Cromer, S. (2009). Promoting gender equality through textbooks. United Nations Educational, Scientific and Cultural Organization.

Cawyer, C. S., Bystrom, D., Miller, J., Simonds, C., O'Brien, M., \& Storey-Martin, J. (1994). Communicating gender equity: Representation and portrayal of women and men in introductory communication textbooks. Communication Studies, 45(3-4), 325-331. https://doi.org/10.1080/10510979409368432

Chandran, S. K. \& M. H. Abdullah (2003). Gender bias in Malaysian English language textbooks. In J. Mukundan (Ed.), Readings on ELT material. Serdang: Universiti Putra Malaysia Press.

Council on Interracial Books for Children (1994) Ten quick ways to analyse children's books for racism and sexism. In Rethinking our Classrooms: Teaching for Equity and Justice (pp. 14-15). Milwaukee, Wisconsin: Rethinking Schools.

Dominguez, L. M. (2003). Gender textbook evaluation. A paper submitted to CELS as course requirement for the degree of master of arts in teaching English as a second language (TESL/TEFL). University of Birmingham, United Kingdom.

Elliott, D., \& Woodward, A. (1990). Textbooks, curriculum and school improvement. In D. Elliott \& A. Woodward (Eds.), Textbooks and schooling in the United states (pp. 223-232). Chicago: National Society for the Study of Education.

Gharbavi, A., \& Mousavi, S. A. (2012). A content analysis of textbooks: Investigating gender bias as a social prominence in Iranian high school English textbooks. English Linguistics Research, 1(1), 42-49. https://doi.org/10.5430/elr.v1n1p42

Giddens, A. (1989). Sociology polity press. Cambridge: Cambridge University Press.

Gillborn, D. (1990). Race, ethnicity and education: teaching and learning in multi-ethnic schools. London: Unwin Hyman.

Gillborn, D. (2003). Race, ethnicity and education: Teaching and learning in multi-ethnic schools. Routledge. https://doi.org/10.4324/9780203400265

Gullicks, K. A., Pearson, J. C., Child, J. T., \& Schwab, C. R. (2005). Diversity and power in public speaking textbooks. Communication Quarterly, 53(2), 247-258. https://doi.org/10.1080/01463370500089870

Hall, M. (2014). Gender representation in current EFL textbooks in Iranian secondary schools. Journal of Language Teaching and Research, 5(2), 253-261. https://doi.org/10.4304/jltr.5.2.253-261

Hanson, T. L. (1999). Gender sensitivity and diversity issues in selected basic public speaking texts. Women and Language, 22(2), 13.

Harrison. B. C. (2010). Power and Society: An introduction to the social science. Harrison: Cengage Learning. https://doi.org/10.1007/978-1-137-07077-7__1

Hartman, J., \& Judd, E. L. (1978). Sexism and TESOL materials. TESOL Quarterly 12, 383-393. https://doi.org/10.2307/3586137

Hellinger, M. (1980). For men must work, and women must weep: Sexism in English Language textbooks used in German schools. Women's Studies International Quarterly 3, 267-275. https://doi.org/10.1016/S0148-0685(80)92323-4

Kantar, R. M. (1977). Men and women of the corporation. New York: Basic Books.

Keating, E. (2009). Language and pragmatics. Language and Linguistics Compass, 3(4), 996-1009. https://doi.org/10.1111/j.1749-818X.2009.00148.X

Khurshid, K., Gillaniz, I. G., \& Hashmi, M. A. (2010). A Study of the Representation of Female Image in the Textbooks of English and Urdu at Secondary School Level. Pakistan Journal of Social Sciences (PJSS), 30(2), 425-437.

Kobia, J. M. (2009). Femininity and masculinity in English primary school textbooks in Kenya. The

42 Consortia Academia Publishing (A partner of Network of Professional Researchers and Educators) 
International Journal of Language Society and Culture, 28, 57-71.

Lesikin, I. (2001). Determining social prominence: A methodology for uncovering gender bias in ESL textbooks. In D. R. Hall \& A. Hewing (Eds), Innovation in English Language Teaching (pp. 275-282). London: Rutledge.

Liew, P. C. (2007). An analysis of gender and ethnic representations in Chinese and Malay primary school reading textbooks: Grades 2-6. Unpublished Doctoral dissertation, Tennessee State University, US.

Mineshima, M. (2008). Gender representations in an EFL textbook. Bulletin of Niigata Institute of Technology, 13, 121-140.

Ndura, E. (2004). ESL and cultural bias: An analysis of elementary through high school textbooks in the Western United States of America Language. Culture and Curriculum, 17(2), 143-153. https://doi.org/10.1080/07908310408666689

Oakley, A. (1972). Sex, Gender, and Society. New York: Harper and Row.

Paivandi, S. (2008). Discrimination and Intolerance in Iran's Textbooks. New York: Freedom House.

Peterson, E. E. (1991). Moving toward a gender balanced curriculum in basic speech communication courses. Communication Education, 40(1), 60-72. https://doi.org/10.1080/03634529109378826

Porreca, K. L. (1984). Sexism in current ESL textbooks. TESOL quarterly, 18(4), 705-724. https://doi.org/10.2307/3586584

Roohani, A., \& Heidari, N. (2012). Evaluating an instructional textbook: A critical discourse perspective. Issues in Language Teaching, 1(1), 123-159.

Seng, T. C. (2003). Gender: The missing factor in the selection of materials. In J. Mukundan (Ed.), Readings on ELT Material (pp. 118- 127). Serdang: Universiti Putra Malaysia Press.

Shimahara, N. K., Holowinsky, I. Z., \& Tomlinson-Clarke, S. (Eds.). (2001). Ethnicity, race, and nationality in education: a global perspective. Routledge. https://doi.org/10.4324/9781410601780

Sileo, T. W., \& Prater, M. (1998). Preparing professionals for partnerships with parents of students with disabilities: Textbook considerations regarding cultural diversity. Exceptional Children, 64(4), 513-528. https://doi.org/10.1177/001440299806400407

Stockdale, D. A. (2006). Gender representations in an EFL textbook. Unpublished master's thesis, University of Birmingham, UK.

Sunderland, J. (2000). Issues of gender representations in textbooks: A state of the art studies. Language Teaching, 33(4), 203- 223. https://doi.org/10.1017/S0261444800015688

Tajeddin, Z \& Janebi Enayat, M. (2010). Gender representation and stereotyping in ELT textbooks: A critical image analysis. TELL, 4(2), 51-79.

Ullah, H., \& Skelton, C. (2013). Gender representation in the public sector schools' textbooks of Pakistan. Educational Studies, 39(2), 183-194. https://doi.org/10.1080/03055698.2012.702892

Vahdatinejad, S. (2018). A Teachers' survey on portrayal of sexism in the images of Iranian EFL school textbooks. PEOPLE: International Journal of Social Sciences, 4(2).268 287. https://doi.org/10.20319/pijss.2018.42.268287

Van Dijk, T. (1998). Critical discourse analysis. In D. Schiffrin, D. Tannen \& H. E. Hamilton (Eds.), The handbook of discourse analysis (pp. 352-371). Massachusetts: Blackwell Publishers.

Wallman, S. (Ed.) (1979), Ethnicity at work. London: Macmillan. https://doi.org/10.1007/978-1-349-16044-0

Weedon, C. (1987). Feminist practice and poststructuralist theory. Oxford: Blackwell.

Weninger, C., \& Williams, J. P. (2005). Cultural representations of minorities in Hungarian textbooks. Pedagogy, Culture \& Society, 13(2), 159-180. https://doi.org/10.1080/14681360500200222

Whiteley, P. (1996). The gender fairness of integrated science textbooks used in Jamaican high schools. International Journal of Science Education, 18(8), 969-976. https://doi.org/10.1080/0950069960180808 
Roohani, A., Sheikhipour, A., \& Farhang, M.

44 Consortia Academia Publishing (A partner of Network of Professional Researchers and Educators) 